\title{
Efeitos de tratamentos térmicos aplicados sobre frutas cítricas armazenadas sob refrigeração
}

\author{
Effects of thermal treatments applied on citric fruits under cold storage
}

\author{
Ricardo Alfredo Kluge ${ }^{1}$ Ricardo Antunes de Azevedo ${ }^{2}$ Maria Luiza Lye Jomori ${ }^{1}$ \\ Fernando Kazuhiro Edagi ${ }^{1}$ Angelo Pedro Jacomino ${ }^{3}$ Salete Aparecida Gaziola ${ }^{2}$ \\ Juan Saavedra del Aguila $^{3}$
}

\section{RESUMO}

Foram aplicados tratamentos térmicos em laranja "Valência", tangor "Murcott" e lima ácida "Tahiti" armazenadas em baixa temperatura e avaliados os efeitos na redução de injúrias pelo frio e sobre outras características bioquímicas. Os seguintes tratamentos foram aplicados: T1: frutas armazenadas $a 1^{\circ} \mathrm{C}$ (Controle); T2: aquecimento rápido das frutas em água quente a $53^{\circ} \mathrm{C}$, durante 3 minutos, sendo, em seguida, armazenadas a $1^{\circ} \mathrm{C}$; T3: aquecimento lento das frutas em câmara regulada para $37^{\circ} \mathrm{C}$, por 2 dias, com posterior armazenamento a $1^{\circ} \mathrm{C}$; e T4: aquecimento intermitente em ciclos de 6 dias a $1^{\circ} \mathrm{C}+1$ dia a $25^{\circ} \mathrm{C}$. As frutas foram armazenadas durante 90 dias a $1^{\circ} \mathrm{C}$ e $90-95 \%$ de Umidade Relativa (UR), sendo avaliadas a cada 15 dias. Além da incidência dos danos, foram avaliadas também as atividades das enzimas antioxidativas (catalase, glutationa redutase $e$ ascorbato peroxidase). A lima ácida “Tahiti” e o tangor "Murcott" suportaram até 90 dias de armazenamento a $1^{\circ} \mathrm{C}$ com aquecimento intermitente, não apresentando danos pelo frio. No tratamento controle (armazenamento contínuo a $1^{\circ} \mathrm{C}$ ), os danos pelo frio surgiram aos 30 dias de armazenamento para a lima "Tahiti" e aos 45 dias para o tangor "Murcott". Em laranjas "Valência”, as injúrias pelo frio surgiram aos 45 dias de armazenamento, sendo significativamente menores no condicionamento térmico. Os efeitos dos tratamentos térmicos no aumento da resistência das frutas ao frio podem estar relacionados com a atividade das enzimas antioxidativas. Para a laranja "Valência", os tratamentos térmicos, aplicados na forma de condicionamento térmico ou aquecimento intermitente, reduzem as injúrias pelo frio e podem prolongar a conservação das frutas a $1{ }^{\circ} \mathrm{C}$ e 90-95\% UR. Para tangor "Murcott" e lima "Tahiti", o aquecimento intermitente é o tratamento mais eficiente para a redução de injúrias pelo frio e para o aumento na capacidade de armazenamento.

Palavras-chave: Citrus sp., injúria pelo frio, enzimas antioxidativas, condicionamento térmico, aquecimento intermitente.

\section{ABSTRACT}

In the present study thermal treatments on, 'Valência' orange, 'Murcott' tangor and 'Tahiti' (temperature conditioning and intermittent warming) were applied lime. The following treatments were applied: T1: Fruits stored at $1^{\circ} \mathrm{C}$ (Controls); T2: Fast heating of the fruits in hot water at $53^{\circ} \mathrm{C}$ for 3 minutes and stored at $1^{\circ} \mathrm{C}$; T3: Slow heating of the fruits in camera regulated at $37^{\circ} \mathrm{C}$ for 2 days, with subsequent storage at $1^{\circ} \mathrm{C}$; and $\mathrm{T} 4$ : Intermittent heating in cycles of 6 days at $1^{\circ} \mathrm{C}+1$ day at $25^{\circ} \mathrm{C}$. Fruits were stored under low temperature $\left(1^{\circ} \mathrm{C}\right)$ and $90-95 \%$ relative humidity $(\mathrm{RH})$ during 90 days. Chilling injury incidence and changes in physical-chemical characteristics were evaluated every 15 days. Activity of catalase, glutathione reductase and ascorbate peroxidase was also determined. Intermittent warming was more efficient than temperature conditioning to reduce chilling injury. 'Tahiti' lime and 'Murcott' tangor supported up to 90 days of intermittent warming stored at $1^{\circ} \mathrm{C}$, while control fruits showed chilling injury after 30 days ('Tahiti' lime) and 45 days ('Murcott' tangor). 'Valência' orange was affected by chilling injury after 45 days of cold storage, and temperature conditioning has caused lower incidence of this disorder. The effect of thermal treatments can be related to the activity of antioxidant enzymes. For 'Valência' orange, thermal treatments, applied as thermal conditioning or intermittent heating, reduce injuries caused by cold and can lengthen the conservation of fruits at $1{ }^{\circ} \mathrm{C}$ and $90-95 \% \mathrm{RH}$. The intermittent heating is the most efficient treatment to reduce injuries caused by cold and increase at storage capacity of the 'Murcott' tangor and 'Tahiti' lime.

Key words: Citrus sp, chilling injury, antioxidant enzymes, temperature conditioning, intermittent warming.

\section{INTRODUÇÃO}

As frutas cítricas são bastante cultivadas no clima tropical de altitude no interior do Estado de

${ }^{1}$ Universidade de São Paulo (USP), Escola Superior de Agricultura “Luiz de Queiroz”(ESALQ), Departamento de Ciências Biológicas, CP 9, 13418-900, Piracicaba, SP, Brasil. E-mail: rakluge@esalq.usp.br. Autor para correspondência.

${ }^{2}$ Departamento de Genética, USP, ESALQ, Piracicaba, SP, Brasil.

${ }^{3}$ Departamento de Produção Vegetal, USP, ESALQ, Piracicaba SP, Brasil. 
São Paulo, tendo como cultivares de destaque a laranja "Valência”, a lima ácida “Tahiti” e o tangor "Murcott”. O período de conservação refrigerado é variável para cada cultivar e depende da temperatura utilizada. Segundo dados de literatura, as condições ótimas para a conservação refrigerada de tangerinas são temperatura de 4 a $7^{\circ} \mathrm{C}$ e $90-95 \%$ de umidade relativa (UR), com as frutas podendo ser armazenadas nestas condições por 14 a 28 dias. Limas ácidas podem ser armazenadas a $9-10^{\circ} \mathrm{C}$, durante 42 a 56 dias, enquanto que, para laranja, a temperatura recomendada é de 3 a $9^{\circ} \mathrm{C}$, com as frutas podendo ser armazenadas durante 21 a 56 dias, dependendo da cultivar e das condições climáticas durante o cultivo (HARDENBURG et al., 1986; CHITARRA \& CHITARRA, 1990; CANTWELL, 2001). Em geral, as frutas cítricas não suportam longos períodos de temperaturas baixas $\left(0\right.$ a $\left.5^{\circ} \mathrm{C}\right)$, e os sintomas de injúrias pelo frio são caracterizados pelo aparecimento de depressões superficiais necróticas na casca.

As injúrias pelo frio constituem as desordens fisiológicas mais comuns e preocupantes em produtos hortícolas armazenados. Elas ocorrem quando os produtos são expostos a temperaturas inferiores à temperatura mínima de segurança (TMS), mas acima do ponto de congelamento. A TMS é variável para os diferentes produtos, variando de 0 a $15^{\circ} \mathrm{C}$, e define a temperatura abaixo da qual os danos podem ocorrer, dependendo do tempo de exposição (CHITARRA \& CHITARRA, 1990; WANG, 1993; KLUGE et al., 2001).

Atualmente não existe nenhum método capaz de evitar completamente os danos pelo frio. $\mathrm{O}$ método básico de controle consiste no armazenamento dos produtos a temperaturas adequadas, ou seja, acima da TMS. Porém, este procedimento pode não ser eficaz para longos períodos de armazenamento, situação em que os sintomas de injúrias pelo frio também podem se manifestar (KLUGE et al., 2001). Assim, outras alternativas vêm sendo testadas, visando a diminuir ou aliviar aqueles danos. As técnicas utilizadas reduzem os danos por meio do retardamento do desenvolvimento dos sintomas ou pelo aumento da tolerância do produto ao frio. Dentre essas técnicas, destacam-se os tratamentos térmicos aplicados antes da refrigeração, na forma de condicionamento, ou durante o armazenamento refrigerado, na forma de aquecimento intermitente. $\mathrm{O}$ condicionamento térmico consiste em expor as frutas a temperaturas moderadas $\left(15\right.$ a $\left.25^{\circ} \mathrm{C}\right)$ ou elevadas $\left(37\right.$ a $\left.53^{\circ} \mathrm{C}\right)$, por curtos períodos, antes de refrigerá-los. Esse tratamento tem reduzido os danos causados pelas baixas temperaturas e diminuído a incidência de podridões em frutas cítricas (BEN-
YEHOSHUA et al., 1987; DEL RIO et al., 1992; GONZALEZ-AGUILAR et al., 1997 e 1998; SCHIRRA \& MULAS, 1993; RODOV et al., 1995 e 2000; PORAT et al., 1999). Já o aquecimento intermitente consiste na interrupção da baixa temperatura de armazenamento, por um ou mais períodos a moderada temperatura (15 a $25^{\circ} \mathrm{C}$ ). Esse tratamento deve ser realizado antes de os danos tornarem-se irreversíveis, o que varia de acordo com o produto (KLUGE et al., 2002). A eficiência no controle de injúrias pelo frio com a aplicação do aquecimento intermitente já foi verificada em algumas frutas cítricas (COHEN, 1988; SCHIRRA \& MULAS, 1995; SCHIRRA \& COHEN, 1999).

Vários sistemas enzimáticos removedores de radicais livres existem nos tecidos e órgãos da planta; as frutas que possuem alta capacidade de metabolizar o peróxido de hidrogênio são mais resistentes à baixa temperatura. SALA (1998) descreve que esta metabolização ocorre por meio da atividade da enzima catalase (CAT), auxiliada pela ascorbato peroxidase (APX), glutationa redutase (GR) e superóxido dismutase (SOD). O autor supra citado verificou que tangerinas "Clementina” são menos sensíveis à baixa temperatura de armazenamento, pois apresentam um sistema antioxidante mais eficiente, mantendo alta a atividade da CAT, APX e GR durante o armazenamento sob baixa temperatura $\left(2,5^{\circ} \mathrm{C}\right)$.

O presente trabalho teve por objetivo verificar o efeito dos tratamentos térmicos sobre a conservação de três cultivares de citros mantidas sob temperatura baixa $\left(1^{\circ} \mathrm{C}\right)$, analisando a incidência de injúrias pelo frio e a atividade das enzimas antioxidativas.

\section{MATERIAL E MÉTODOS}

O projeto foi conduzido no Departamento de Ciências Biológicas da Escola Superior de Agricultura "Luiz de Queiroz" - ESALQ/USP, em Piracicaba, SP, Brasil. Foram realizados experimentos com limas ácidas “Tahiti”, laranja "Valência” e tangor "Murcott”. As frutas foram obtidas na região de MogiMirim, SP. Os seguintes tratamentos foram aplicados: $\mathrm{T} 1$ : frutas armazenadas a $1^{\circ} \mathrm{C}$ (Controle); T2: aquecimento rápido das frutas em água quente a $53^{\circ} \mathrm{C}$, durante três minutos, sendo em seguida armazenadas a $1^{\circ} \mathrm{C}$; T3: aquecimento lento das frutas em câmara regulada para $37^{\circ} \mathrm{C}$ por dois dias, com posterior armazenamento a $1^{\circ} \mathrm{C}$; e T4: aquecimento intermitente em ciclos de seis dias a $1{ }^{\circ} \mathrm{C}+1$ dia a $25^{\circ} \mathrm{C}$. As frutas foram armazenadas a $1^{\circ} \mathrm{C}$ e $90-95 \%$ UR, por períodos de 15, 30, 45, 60 e 75 e 90 dias, sendo que, após cada período de armazenamento, foram expostas à 
temperatura ambiente $\left(25^{\circ} \mathrm{C}\right)$ por três dias, para simular vida de prateleira na comercialização.

O delineamento experimental foi inteiramente ao acaso, em esquema fatorial $4 \times 7$. Os fatores estudados foram tratamentos, em quatro níveis, e período de armazenamento, em sete níveis (incluído o dia inicial). Foram utilizadas quatro repetições de 10 frutas.

Foram determinadas as injúrias pelo frio pela determinação da porcentagem de frutas injuriadas pelo frio (depressões na casca) e estimado o índice de injúrias (severidade) de acordo com a metodologia adaptada de SALA \& LAFUENTE (1999). Relativamente à superfície da casca afetada, as frutas foram classificadas em cinco categorias: $0=$ sem depressões superficiais ( $0 \%$ da superfície afetada), $1=$ pouco ( 1 a $5 \%$ da superfície afetada), 2= médio (5-25\%) e $3=$ severo (25-50\%) e $4=$ muito severo ( $>50 \%$ da superfície afetada).

Para a realização da extração protéica, amostras de cada tratamento foram coletadas, colocadas em moinho com nitrogênio líquido e depois trituradas “a pó” em mortar com nitrogênio líquido, os materiais vegetais foram homogeneizados em tampão de extração fosfato de potássio $100 \mathrm{mM}, \mathrm{pH} 7,5$, contendo $1 \mathrm{mM}$ de EDTA (0,372g L ${ }^{-1}$ tampão), $3 \mathrm{mM}$ de

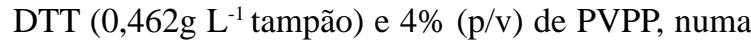
proporção de $3 \mathrm{ml}$ de tampão de extração $\mathrm{g}^{-1}$ de tecido. O homogeneizado foi centrifugado em centrífuga Datamed Jouan B/Br4i de rotor AB 10.12, a 10.732,5g por $30 \mathrm{~min}$ a $4^{\circ} \mathrm{C}$. O sobrenadante foi coletado, dividido em alíquotas e estocado em freezer a $-80^{\circ} \mathrm{C}$ até o momento das análises.

A atividade de catalase - CAT (EC 1.11.1.6) foi determinada como descrito por KRAUS et al. (1995) com algumas modificações, conforme AZEVEDO et al. (1998). ACAT foi determinada espectrofotometricamente a $25^{\circ} \mathrm{C}$, em uma mistura de reação, contendo $1 \mathrm{~mL}$ de tampão fosfato de potássio $100 \mathrm{mM}$, pH 7,5, contendo 2,5 $\mu \mathrm{L}$ de peróxido de hidrogênio (solução de 30\%), preparada imediatamente antes do uso. A reação foi iniciada pela adição de $25 \mu \mathrm{L}$ de extrato e a atividade foi determinada seguindo-se a decomposição de peróxido de hidrogênio por 1min, por alterações na absorbância a $240 \eta m$.

A atividade de glutationa redutase - GR (EC 1.6.4.2) foi determinada espectrofotometricamente a $30^{\circ} \mathrm{C}$, em uma mistura de reação, consistindo de $3 \mathrm{~mL}$ de tampão fosfato de potássio $100 \mathrm{mM}, \mathrm{pH} 7,5$, contendo 1mM 5,5'-ditio-bis(2-ácido nitrobenzoico) (DTNB), 1mM glutationa oxidada e 0,1mM NADPH. A reação foi iniciada pela adição de $50 \mu \mathrm{L}$ de extrato. A GR foi estimada pela redução de glutationa oxidada, que foi monitorada pela alteração da absorbância a 412ๆm.
Na quantificação da atividade da Ascorbato peroxidase - APX (EC 1.11.1.11), foi utilizada a metodologia de ASADA (1984). A mistura da reação consistiu de $650 \mu \mathrm{L}$ de tampão fosfato de potássio

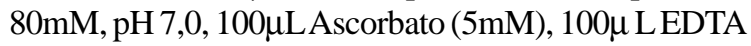

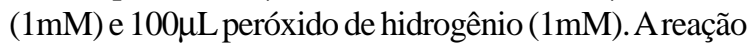
foi iniciada com a adição de $50 \mu \mathrm{L}$ do extrato vegetal. A atividade foi determinada seguindo-se a decomposição de peróxido de hidrogênio por 1min, por alterações na absorbância a 290ๆm. O método de BRADFORD (1976) foi utilizado para as determinações da concentração de proteínas totais, utilizando-se BSA como padrão.

Os dados foram submetidos à análise de variância (teste F), sendo que foram determinadas as diferenças mínimas significativas (d.m.s.). As diferenças entre dois tratamentos maiores que a soma de dois desvios-padrão foram consideradas significativas a $5 \%$ de probabilidade de erro.

\section{RESULTADOS E DISCUSSÃO}

Em laranjas "Valência”, as injúrias pelo frio surgiram aos 45 dias de armazenamento, sendo significativamente menores nos condicionamentos térmicos. Para a lima "Tahiti" e o tangor "Murcott”, os danos pelo frio surgiram aos 30 e 45 dias, respectivamente. $\mathrm{O}$ condicionamento térmico lento ( $37^{\circ} \mathrm{C}$ durante dois dias) ocasionou queimaduras na casca da laranja "Valência” (em mais de 80\% das frutas) não associadas ao frio, mas ao estresse resultante da alta temperatura à qual as frutas foram submetidas antes da refrigeração. Este tipo de dano foi confirmado em testes subseqüentes e não ocorreu na lima "Tahiti” e no tangor "Murcott".

$\mathrm{O}$ aquecimento intermitente, de maneira geral, proporcionou as menores incidências de injúrias pelo frio na lima “Tahiti” e no tangor "Murcott”, sendo que, nesta última, o aquecimento lento foi igualmente eficaz (Figura 1). A redução de injúrias pelo frio por meio de tratamentos térmicos também foi observada por outros autores (BEN-YEHOSHUA et al., 1987; DEL RIO et al., 1992; GONZALEZ-AGUILAR et al., 1997; 1998; SCHIRRA \& MULAS, 1993; 1995; RODOV et al., 1995; 2000; PORAT et al., 1999).

A lima “Tahiti” suportou até 90 dias de armazenamento quando aplicado o tratamento de aquecimento intermitente, enquanto que, para os outros tratamentos, as frutas foram sendo descartadas devido à alta incidência de injúrias pelo frio.

As atividades específicas das enzimas catalase (CAT), glutationa redutase (GR) e ascorbato peroxidase (APX) nas três cultivares avaliadas se encontram nas figuras 2, 3 e 4 . Verificou-se que a 


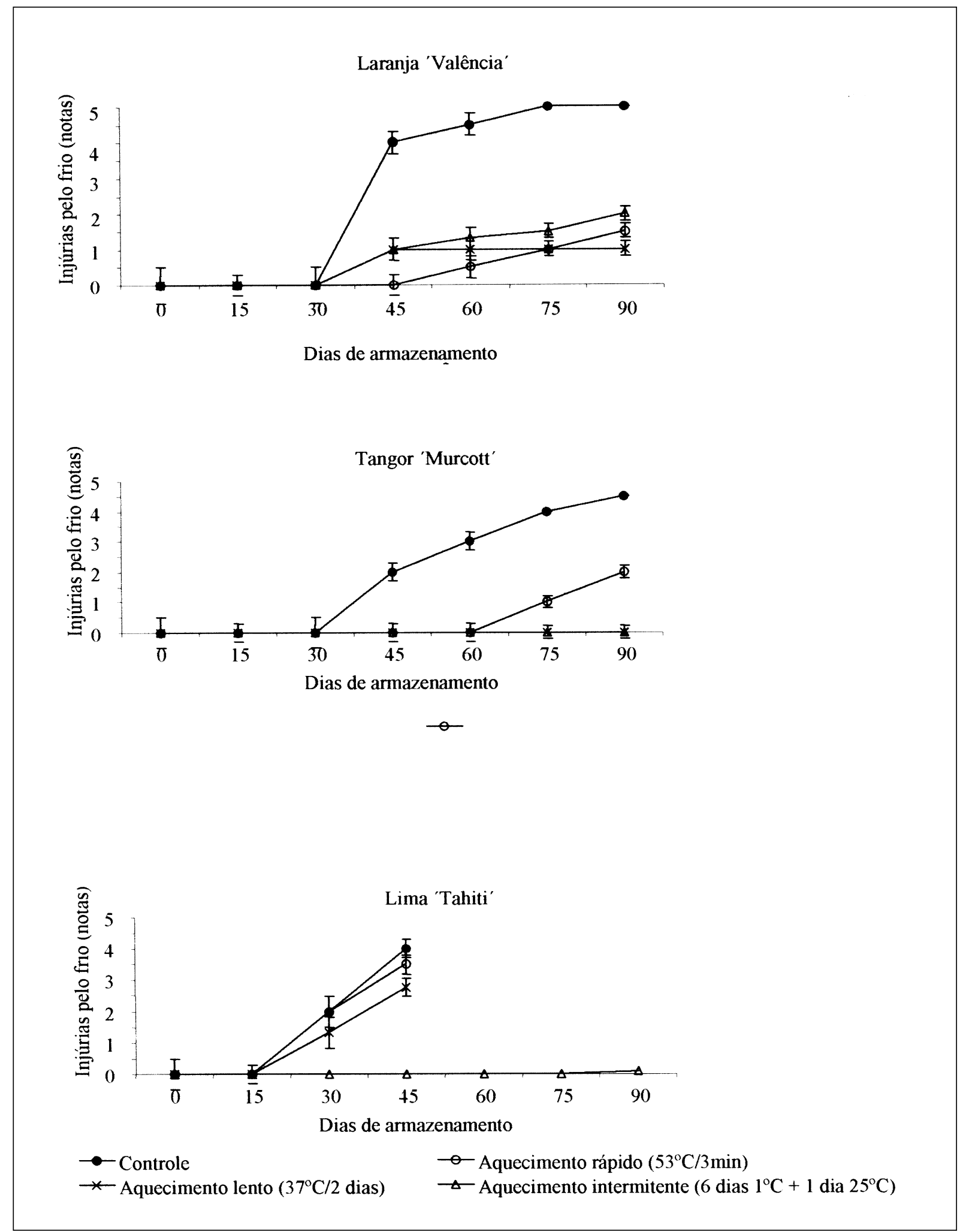

Figura 1 - Efeito dos diferentes tratamentos sobre as injúrias pelo frio (notas) em laranja "Valência”, tangor "Murcott" e lima ácida “Tahiti”. Notas: $0=$ sem depressões superficiais ( $0 \%$ da superfície afetada), 1 = pouco ( 1 a $5 \%$ da superfície afetada), $2=$ médio $(5-25 \%)$ e $3=$ severo $(25-50 \%)$ e $4=$ muito severo (> 50\% da superfície afetada). Barras verticais representam o desvio padrão da média $(n=4)$.

Ciência Rural, v.36, n.5, set-out, 2006. 

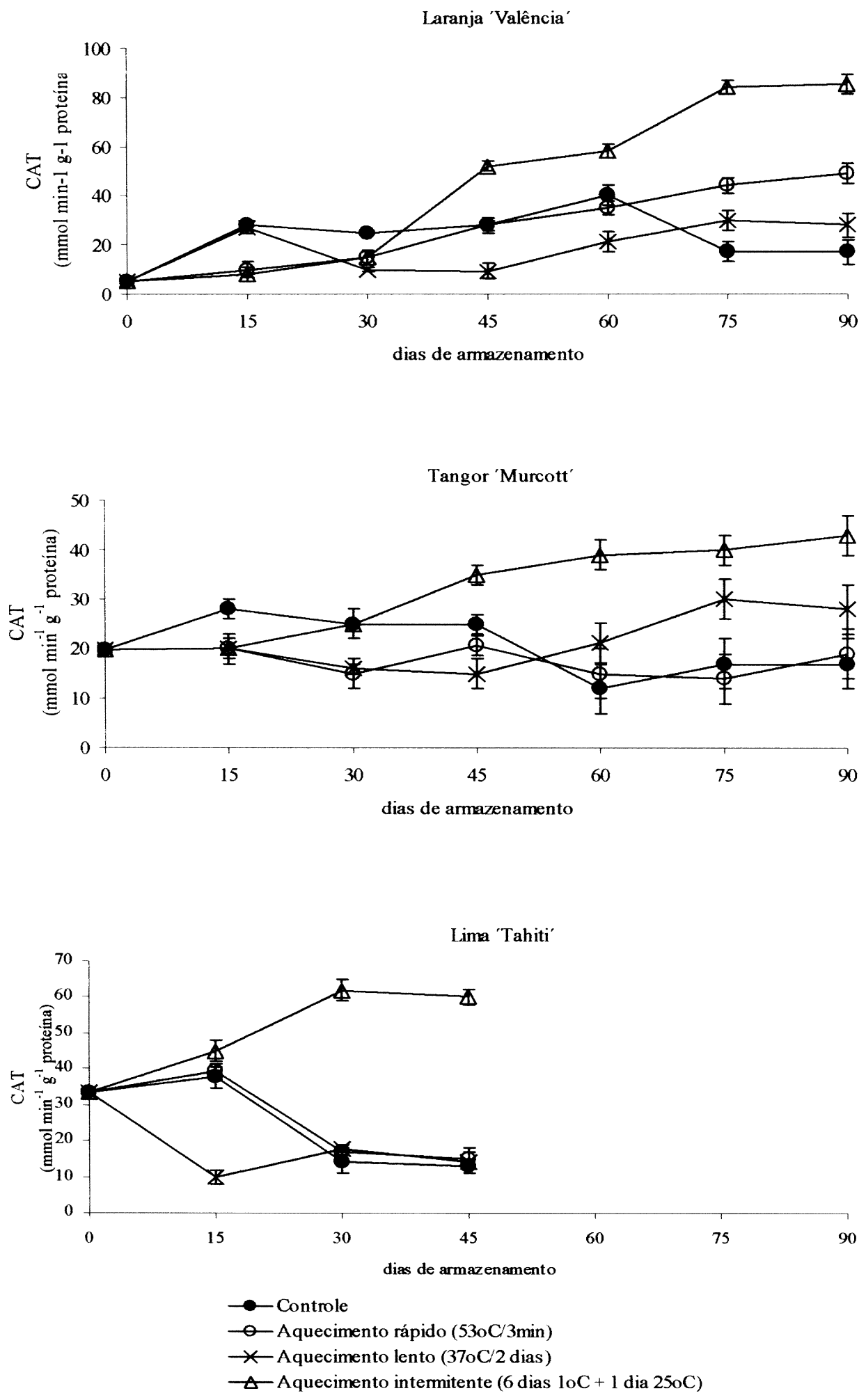

Figura 2 - Atividade específica da Catalase (CAT) em laranja "Valência”, tangor “Murcott" e lima "Tahiti" armazenadas a $1^{\circ} \mathrm{C}$, em função dos tratamentos aplicados. Barras verticais representam o desvio padrão da média $(n=4)$.

Ciência Rural, v.36, n.5, set-out, 2006. 


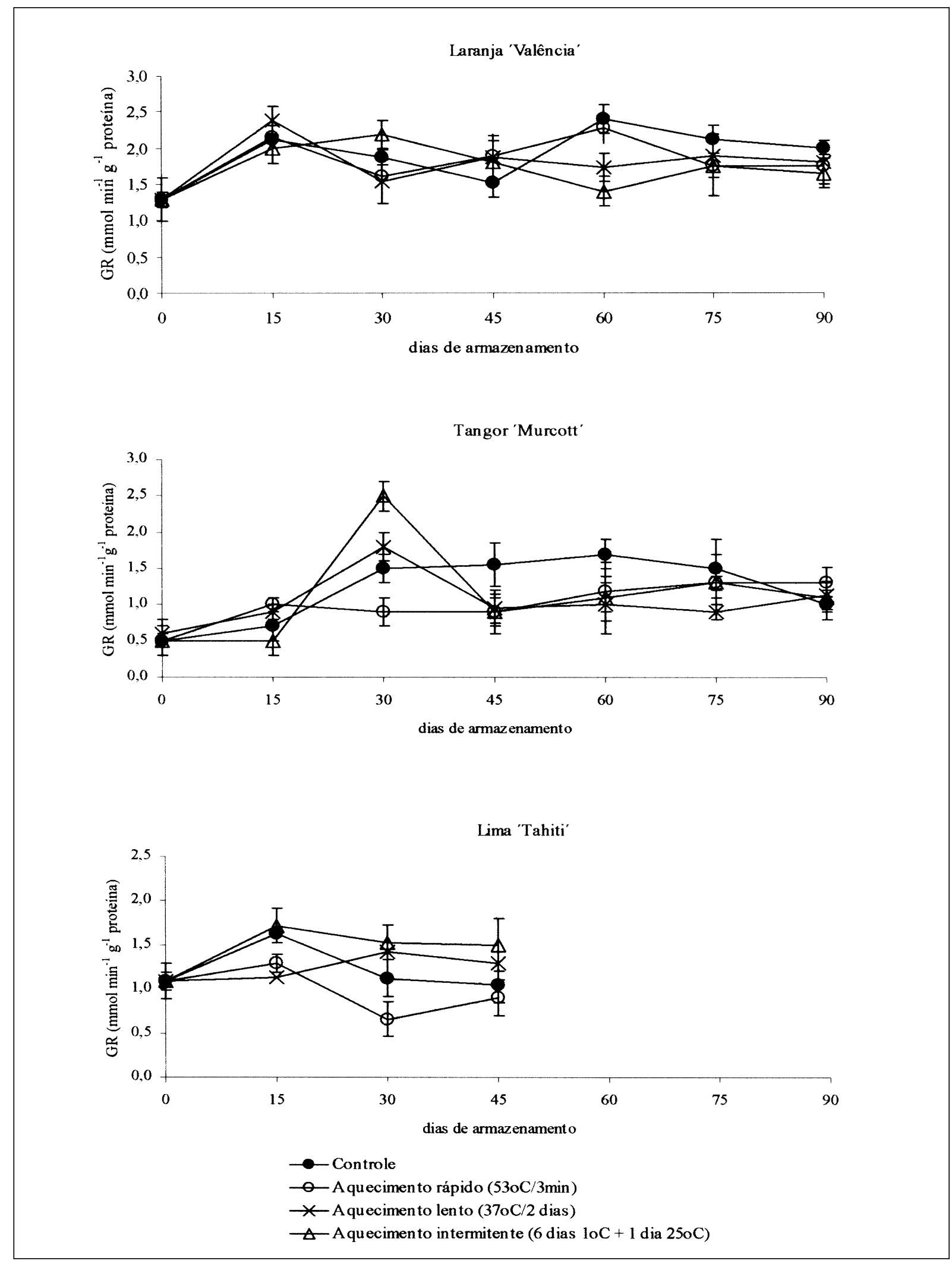

Figura 3 - Atividade específica da Glutationa redutase (GR) em laranja "Valência”, tangor "Murcott” e lima “Tahiti” armazenados a $1^{\circ} \mathrm{C}$, em função dos tratamentos aplicados. Barras verticais representam o desvio padrão da média $(\mathrm{n}=4)$

Ciência Rural, v.36, n.5, set-out, 2006. 


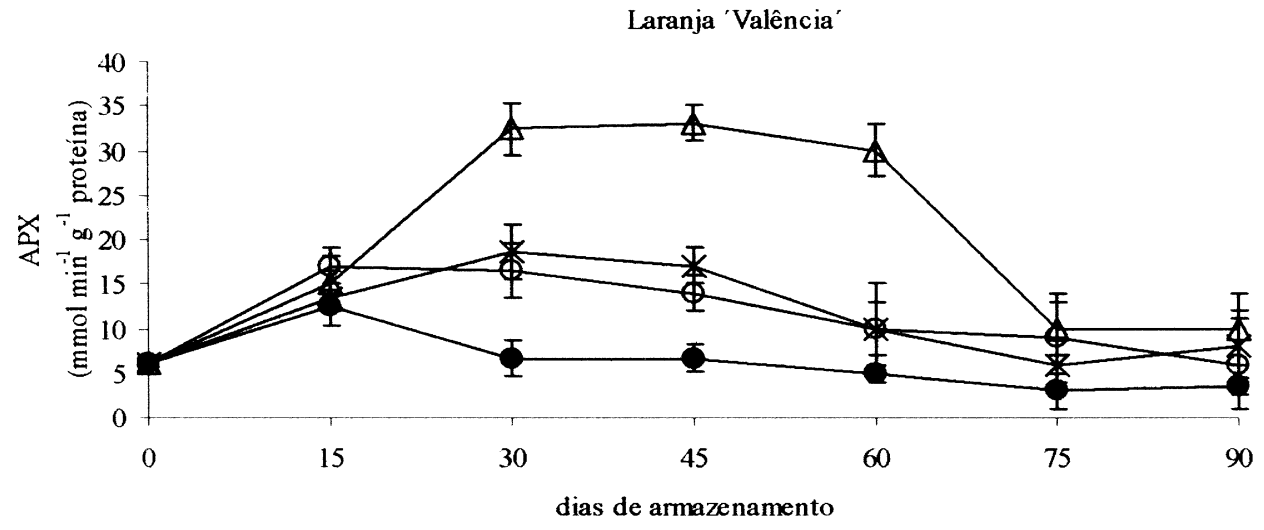

Tangor 'Murcott'

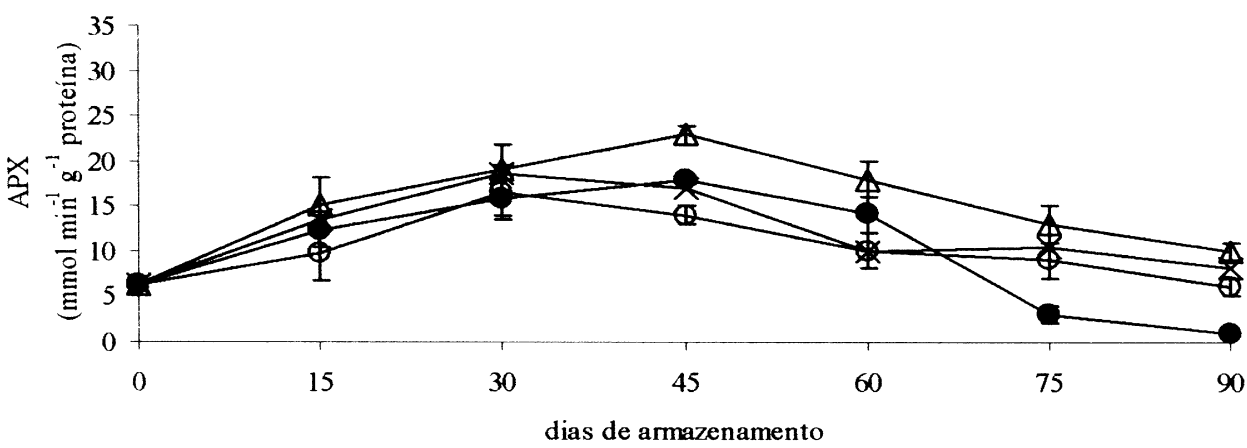

Lima 'Tahiti'

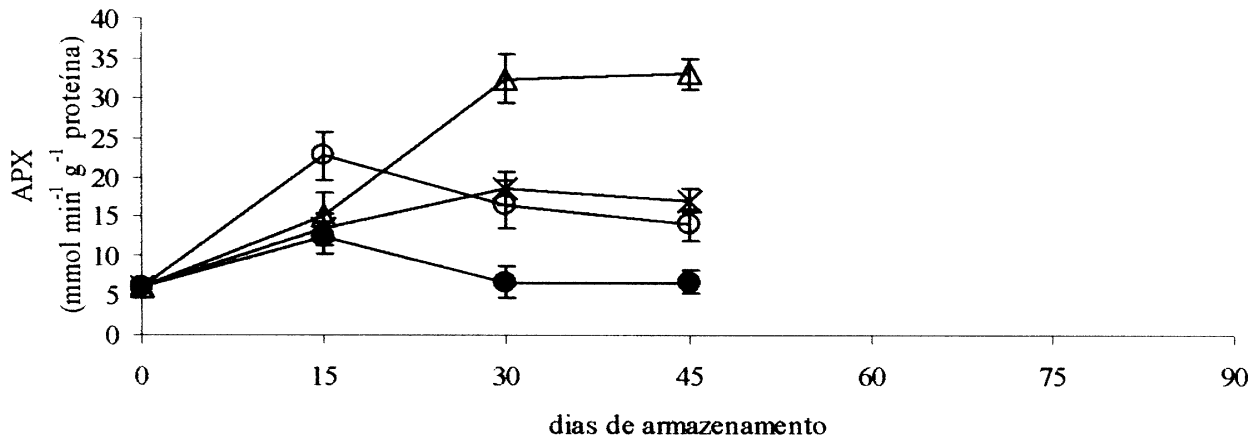

$\rightarrow$ Controle

- Aquecimento rápido $(53 \mathrm{oC} / 3 \mathrm{~min})$

$\leftarrow$ Aquecimento lento $(37 \mathrm{oC} / 2$ dias $)$

$\triangle$ Aquecimento intermitente $(6$ dias $10 \mathrm{C}+1$ dia $250 \mathrm{C})$

Figura 4 - Atividade específica do Ascorbato peroxidase (APX) em laranja "Valência”, tangor "Murcott” e lima "Tahiti” armazenados a $1^{\circ} \mathrm{C}$, em função dos tratamentos aplicados. Barras verticais representam o desvio padrão da média $(n=4)$.

Ciência Rural, v.36, n.5, set-out, 2006. 
atividade da CAT foi maior no tratamento com aquecimento intermitente em relação ao controle durante todo o período de armazenamento na lima ácida “Tahiti” e a partir dos 45 dias de armazenamento na laranja e no tangor (Figura 2), enquanto que, para o condicionamento térmico (lento ou rápido), não se constatou este tipo de resposta. Em relação à atividade da GR, verificaram-se poucas diferenças na laranja "Valência” em função dos tratamentos (Figura 3), enquanto que, para o tangor "Murcott", foi verificado um pico na atividade da GR no $30^{\circ}$ dia para as frutas que sofreram aquecimento intermitente. Para a lima “Tahiti”, houve uma maior atividade da GR no $30^{\circ}$ e no $45^{\circ}$ dia de armazenamento do tratamento aquecimento intermitente em relação ao controle. Para a APX, verificou-se na laranja "Valência” que sofreu aquecimento intermitente, alta atividade no $30^{\circ}$, no $45^{\circ}$ e no $60^{\circ}$ dia de armazenamento (Figura 4). No tangor "Murcott", a atividade da APX no tratamento com aquecimento intermitente foi um pouco superior à do controle ao longo do armazenamento, enquanto que, para a lima "Tahiti”, houve uma maior atividade da APX após 30 e 45 dias de armazenamento neste mesmo tratamento.

A metabolização do peróxido de hidrogênio ocorre por meio da atividade da CAT, auxiliada por outras enzimas, tais como a APX e a GR (SALA, 1998). No presente trabalho, particularmente, a atividade da CAT parece ter sido a responsável, em grande parte, pela eliminação ou redução dos compostos que causariam danos às células vegetais. $\mathrm{O}$ aquecimento intermitente poderia ser uma forma de remover substâncias tóxicas que estariam sendo acumuladas durante a exposição à baixa temperatura, conforme foi sugerido por WANG (1994). Outros autores afirmaram que a CAT parece ser a principal enzima antioxidativa envolvida no mecanismo de defesa de tangerinas "Clementina” contra as injúrias pelo frio, mas que outras enzimas também poderiam estar participando deste mecanismo de defesa (SALA \& LAFUENTE, 2000).

A maior atividade da CAT nas três cultivares submetidas ao aquecimento intermitente pode ter contribuído para a redução dos danos pelo frio nas frutas. Segundo alguns autores, os tratamentos térmicos podem ser utilizados para induzir a atividade das enzimas antioxidativas ou para evitar a queda na sua atividade durante o armazenamento (WANG, 1995; SALA \& LAFUENTE, 1999; 2000).

Uma das principais respostas dos vegetais aos estresses bióticos ou abióticos (como o frio) é a aceleração na produção das espécies reativas de oxigênio. O balanço entre a formação e a detoxificação destas espécies é crítico para a sobrevivência da célula
(MITTLER, 2002). A detoxificação está relacionada diretamente com a atividade das enzimas antioxidativas. Diferenças na atividade das enzimas antioxidativas entre duas cultivares de citros tolerantes ao frio (mandarinas “Clementina” e "Clemenules”) e uma cultivar sensível ao frio ("Fortune") foi verificada por SALA (1998), fato semelhante ao observado no presente trabalho. Assim, a atividade do sistema antioxidante, responsável pela metabolização de substâncias tóxicas e pelo aumento da resistência das frutas ao frio é dependente da cultivar, e a associação das várias enzimas pertencentes a este sistema parece ser um fator determinante na longevidade das frutas em baixas temperaturas.

\section{CONCLUSÕES}

Para a laranja "Valência”, os tratamentos térmicos, aplicados na forma de condicionamento térmico ou aquecimento intermitente, reduzem as injúrias pelo frio e podem prolongar a conservação das frutas a $1^{\circ} \mathrm{C}$ e $90-95 \%$ UR. Para o tangor "Murcott” e a lima "Tahiti”, o aquecimento intermitente é o tratamento mais eficiente para a redução de injúrias pelo frio e para o aumento na capacidade de armazenamento.

\section{AGRADECIMENTOS}

Os autores agradecem à Fundação de Amparo à Pesquisa do Estado de São Paulo(FAPESP) pelo suporte financeiro fornecido a este trabalho (proc. $\mathrm{N}^{\circ}$ 01/13433-5) e pelas bolsas de estudo do terceiro, do quarto e do sétimo autor, como também ao Conselho Nacional de Desenvolvimento Científico e Tecnológico (CNPq), pela bolsa de produtividade em Pesquisa do primeiro autor.

\section{REFERÊNCIAS}

ASADA, K. Assay of ascorbate-specific peroxidase. Methods Enymological, v.105, p.427-429, 1984.

AZEVEDO, R.A. et al. Response of antioxidant enzymes to transfer from elevated carbon dioxide to air and ozone fumigation, in the leaves and roots of wild-type and a catalasedeficient mutant of barley. Physiologia Plantarum, v.104, p.280-292, 1998 .

BRADFORD, M.M. A rapid and sensitive method for the quantitatin of microgram quantities of protein utilizing the principle of protein-dye binding. Analytical Biochemistry, v.72, p.248-254, 1976.

BEN-YEHOSHUA, S. et al. Individual seal-packaging enables the use of curing at high temperatures to reduce decay and heal injury of citrus fruits. HortScience, v.22, p.777-783, 1987.

CANTWELL, M.T. Properties and recommended conditions for long-term storage of fresh fruits and vegetables. Capturado em 11 jan. 2001. Online. Disponível na Internet: http:www.postharvest.ucdavis.edu 
COHEN, E. Commercial use of long-term storage of lemon with intermittent warming. HortScience, v.23, n.2, p.400, 1988.

CHITARRA, M.I.; CHITARRA, A.B. Pós-colheita de frutos e hortaliças: fisiologia e manuseio. Lavras: ESAL/FAEPE, 1990. 320p.

DEL RIO, M.A. et al. Effects of postharvest curing at high temperature on decay and quality of "Marsh" grapefruits and navel orange. In: TRIBULATO, E. et al. (Ed). Proceedings of the International Society of Citriculture, v.3, p.10811083, 1992.

GONZALEZ-AGUILAR, G.A. et al. Ripening affects hightemperature-induced polyamines and their changes during cold storage of hybrid Fortune mandarins. Journal of Agriculture and Food Chemistry, v.46, p.3503-3508, 1998.

GONZALEZ-AGUILAR, G.A. et al. Temperature and duration of water dips influence chilling injury, decay and polyamine content in "Fortune" mandarins. Portharvest Biology and Technology, v.12, p.61-69, 1997.

HARDENBURG, R.E. et al. The commercial storage of fruits, vegetables, and florist, and nursery stocks. Washington: USDA, 1986. 130p. (USDA. Agriculture Handbook, 66).

KRAUS, T.E. et al. Paclobutrazol-induced tolerance of wheat leaves to paraquat may involve increased antioxidant enzyme activity. Journal of Plant Physiology, v.145, p.570-576, 1995.

KLUGE, R.A. et al. Fisiologia e manejo pós-colheita de frutas de clima temperado. 2.Ed. Campinas: Livraria e Editora Rural, 2002. 214p.

KLUGE, R.A. et al. Distúrbios fisiológicos em frutos. Piracicaba: FEALQ, 2001. 58p.

MITLER, R. Oxidative stress antioxidants and stress tolerance. Trends in Plant Science, v.7, n.9, p.405-410, 2002.

PORAT, R. et al. Effects of ethylene and 1-methylcyclopropene on the postharvest qualities of "Shamouti" oranges.
Postharvest Biology and Technology, v.15, n.2, p.155-163, 1999.

RODOV, V. et al. Effect of combined application of heat treatments and plastic packaging on keeping quality of "Oroblanco" fruit (Citrus grandis L. x C. paradisi Macf.). Postharvest Biology and Technology, v.20, p.287-294, 2000 .

RODOV, V. et al. Reducing chilling injury and decay of stored citrus fruit by hot water dips. Postharvest Biology and Technology, v.5, p.119-127, 1995.

SALA, J.M. Involvement of oxidative stress in chilling injury in cold-stored mandarin fruits. Postharvest Biology and Technology, v.13, p.255-161, 1998.

SALA, J.M.; LAFUENTE, M.T. Catalase enzyme activity is related to tolerance of mandarin fruits to chilling. Postharvest Biology and Technology, v.20, p.81-89, 2000.

SALA, J.M.; LAFUENTE, M.T. Catalase in the heat-induced chilling tolerance of cold-stored hybrid Fortune mandarin fruits. Journal of Agriculture and Food Chemistry, v.47, p.24102414, 1999.

SCHIRRA, M.; COHEN, E. Long-term storage of "Olinda" oranges under chilling and intermittent warming temperatures. Postharvest Biology and Technology, v.16, p.63-69, 1999.

SCHIRRA, M.; MULAS, M. "Fortune” mandarin quality following prestorage water dips and intermittent warming during cold storage. HortScience, v.30, n.3, p.560-551, 1995.

SCHIRRA, M.; MULAS, M. Keeping quality of “Oroblanco” grapefruit-type as affected by hot dip treatments. Advances in Horticultural Science, v.7, p.73-76, 1993.

WANG, C.Y. Approaches to reduce chilling injury of fruits and vegetables. Horticultural Reviews, v.15, p.63-95, 1993.

WANG, C.Y. Chilling injury of tropical horticultural commodities. HortScience, v.29, n.9, p.986-988, 1994.

WANG, C.Y. Effect of temperature preconditioning on catalase, peroxidase, and superoxide dismutase in chilled zucchini squash. Postharvest Biology and Technology, v.5, p.67-76, 1995. 